\title{
Solution Phase, Solid State, and Theoretical Investigations on the MacMillan Imidazolidinone
}

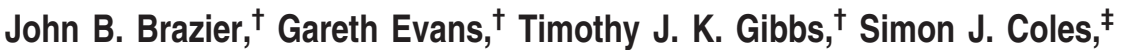 \\ Michael B. Hursthouse, ${ }^{\ddagger}$ James A. Platts, ${ }^{\dagger, *}$ and Nicholas C. O. Tomkinson ${ }^{\star, \dagger}$ \\ School of Chemistry, Main Building, Cardiff University, Park Place, \\ Cardiff, CF10 3AT, United Kingdom, and Department of Crystallography, School of \\ Chemistry, Southampton University, Southampton, SO17 1BJ, United Kingdom
}

tomkinsonnc@cardiff.ac.uk

Received October 30, 2008

\section{ABSTRACT}

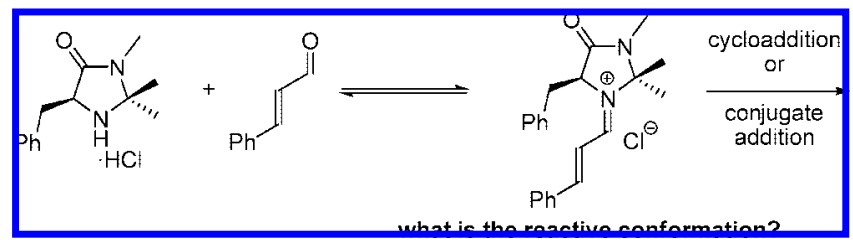

A combination of solution phase NMR, X-ray crystallographic studies, and DFT calculations provide a consistent structural conformation for iminium ions derived from the MacMillan imidazolidinone.

The concept of iminium ion catalysis using chiral secondary amines was developed by MacMillan in 2000. ${ }^{1}$ Since then, the field has expanded to encompass a broad spectrum of cycloaddition and conjugate addition reactions that proceed in high yield and with exceptional levels of asymmetric induction. $^{2}$ As the area has matured, two principal scaffolds have emerged from extensive investigations as general catalysts of broad applicability: the imidazolidinones $\mathbf{1}$ and $\mathbf{2}$ and the diarylprolinol ethers $\mathbf{3}$ and $\mathbf{4}$ (Figure 1). ${ }^{2}$ Imidazolidinone $\mathbf{1}$ is effective for various classes of cycloaddition $\left([4+2],{ }^{1}[3+2],{ }^{3}[4+3]^{4}\right)$, and has been elegantly applied in a number of target syntheses, ${ }^{5}$ but for conjugate additions low ee's have limited its scope to the

\footnotetext{
† Cardiff University.

$\doteqdot$ Southampton University.

(1) Ahrendt, K. A.; Borths, C. J.; MacMillan, D. W. C. J. Am. Chem. Soc. 2000, 122, 4243.

(2) Erkkilä, A.; Majander, I.; Pihko, P. M. Chem. Rev. 2007, 107, 5416.

(3) Jen, W. S.; Wiener, J. J. M.; MacMillan, D. W. C. J. Am. Chem. Soc. 2000, 122, 9874.

(4) Harmata, M.; Ghosh, S. K.; Hong, X.; Wacharasindhu, S.; Kirchhoefer, P. J. Am. Chem. Soc. 2003, 125, 2058.
}

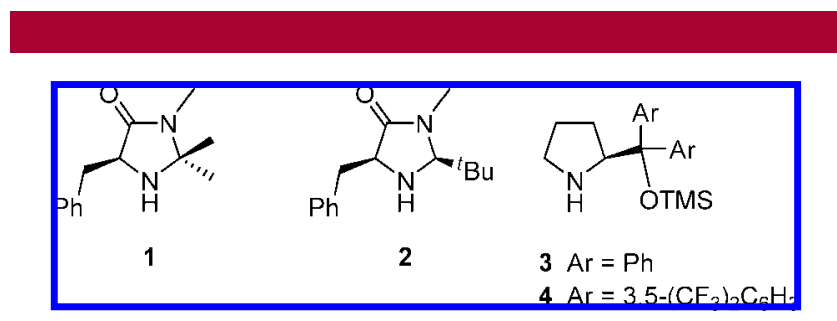

Figure 1. Principal catalysts for iminium ion catalyzed transformations.

addition of pyrroles. ${ }^{6}$ For conjugate addition reactions, imidazolidinone $\mathbf{2}$ has emerged as the imidazolidinone

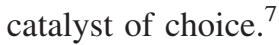

The first report, describing the use of imidazolidinone $\mathbf{1} \cdot \mathrm{HCl}$, proposed a model to explain the high enantiofacial

(5) For example, see: (a) Kinsman, A. C.; Kerr, M. A. J. Am. Chem. Soc. 2003, 125, 14120. (b) Wilson, R. M.; Jen, W. S.; MacMillan, D. W. C. J.Am. Chem. Soc. 2005, 127, 11616. (c) Selkälä, S. A.; Koskinen, A. M. P. Eur. J. Org. Chem. 2005, 1620. (d) Satoh, N.; Akiba, T.; Yokoshima, S.; Fukuyama, T. Angew. Chem. Int. Ed. 2007, 46, 5734. (e) Gilmour, R.; Prior, T. J.; Burton, J. W.; Holmes, A. B. Chem. Commun. 2007, 3954. (6) Paras, N. A.; MacMillan, D. W. C. J. Am. Chem. Soc. 2001, 123, 4370 . 
discrimination of the dienophile in which the benzyl arm of the catalyst sits directly over the reactive $\pi$-system of the iminium ion (A) (Figure 2). ${ }^{1}$ This orientation was thought

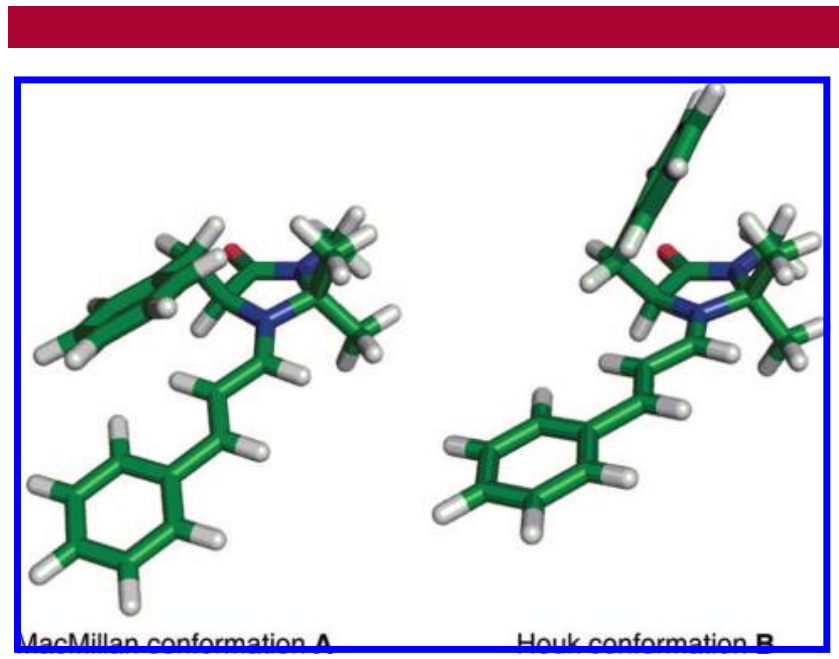

Figure 2. Proposed MacMillan and Houk reactive conformations.

necessary to direct approach of the diene from the $S i$-face of the iminium ion. Subsequent DFT calculations undertaken by Houk have disputed this suggesting the preferred conformation of the iminium ion intermediate in the gas phase places the benzyl arm over the imidazolidinone ring $(\mathbf{B})$, where it is still able to direct reaction of the iminium ion from the lower face with the diene. ${ }^{8}$ Furthermore, these studies have linked the accessible geometries of the intermediate iminium ions with related transition structures leading to the observed products. However, both structures were proposed on the basis of gas-phase theoretical models, using approximate methods such as molecular mechanics or hybrid density functional theory. Neither method can be expected to give reliable predictions for the weak interactions ( $\pi-\pi$ stacking, $\mathrm{C}-\mathrm{H} \cdot \cdots \pi \mathrm{H}$-bonding) that determine conformational preference in this structure. To date, no experimental verification of the conformation adopted by this key intermediate has been reported, a shortfall this work seeks to address.

As part of our investigations into iminium ion catalyzed transformations, ${ }^{9}$ we sought to gain further evidence for the behavior of imidazolidinone derived iminium ions in solution to ascertain whether these results, and those from our own calculations, were borne out by experiment. Establishing this link between theory and experiment will provide further insight into this important class of reaction, give confidence

(7) For a review on the use of imidazolidinone catalysts, see: Lelais, G.; MacMillan, D. W. C. Aldrichimica Acta 2006, 39, 79.

(8) (a) Gordillo, R.; Houk, K. N. J. Am. Chem. Soc. 2006, 128, 3543. (b) Gordillo, R.; Carter, J.; Houk, K. N. Adv. Synth. Catal. 2004, 346, 1175.

(9) (a) Evans, G.; Gibbs, T. J. K.; Jenkins, R. L.; Coles, S. J.; Hirsthouse, M. B.; Platts, J. A.; Tomkinson, N. C. O. Angew. Chem., Int. Ed. 2008, 47, 2820. (b) Cavill, J. L.; Elliott, R. L.; Evans, G.; Jones, I. L.; Platts, J. A.; Ruda, A. M.; Tomkinson, N. C. O. Tetrahedron 2006, 62, 410. (c) Evans, G. J. S.; White, K.; Platts, J. A.; Tomkinson, N. C. O. Org. Biomol. Chem. 2006, 2616. (d) Cavill, J. L.; Peters, J.-U.; Tomkinson, N. C. O. Chem. Commun. 2003, 728. in theoretical models and aid future catalyst design. In this communication we present the first experimental evidence from solution and solid phases, along with further theoretical data, for the preferred conformation of $\mathbf{1}$ and its derived iminium ions.

Our investigations began with the preparation and isolation of a series of iminium ions derived from the imidazolidinone 1 and cinnamaldehyde. Addition of cinnamaldehyde to a methanolic solution of $1 \cdot \mathrm{HPF}_{6}$ caused precipitation of a bench stable iminium ion $\mathbf{5}$ which could be isolated by filtration and easily manipulated in air. Crystals suitable for X-ray analysis could be grown from $\mathrm{MeCN}$ (Figure 3). In a similar

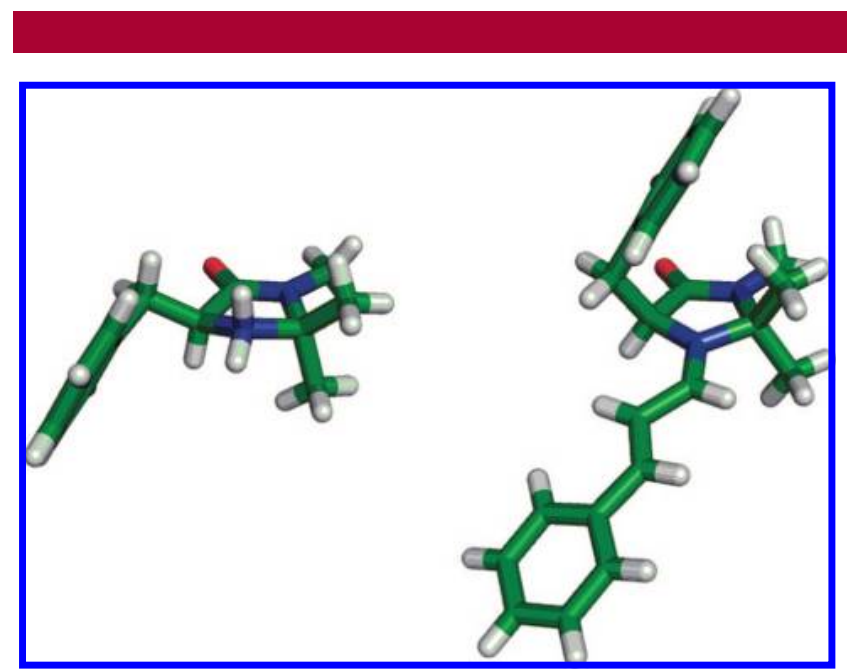

Figure 3. X-Ray structures of imidazolidinone $\mathbf{1} \cdot \mathrm{HPF}_{6}$ and iminium ion 5 (counterions omitted for clarity).

manner, we obtained crystal structures containing $\mathrm{ClO}_{4}{ }^{-}$(6) and $\mathrm{BF}_{4}^{-}$(7) counteranions (see Supporting Information for full details). All such structures (5-7) are highly similar ( rmsd $<0.6 \AA$ ), with the iminium $\pi$-system adopting the expected $(E)$-geometry and importantly, the benzyl arm over the imidazolidinone ring (conformation $\mathbf{B}$ ) in agreement with the calculations of Houk. In contrast, the single crystal X-ray structure of the parent imidazolidione $\mathbf{1} \cdot \mathrm{HPF}_{6}$ (Figure 3 ) shows the benzyl arm pointing away from the imidazolidinone ring, as previously identified in the hydrochloride salt $\mathbf{1} \cdot \mathrm{HCl}{ }^{10}$ These represent the first experimental structural data for imidazolidinone derived iminium ions, and thus provide evidence for the mode of chiral induction in this important class of organocatalysis.

Having established the geometry of the intermediates in the solid state, we examined the behavior of the imidazolidinone ring system and the derived iminium ions in solution (Figure 4). The ${ }^{1} \mathrm{H} \mathrm{NMR}\left(\mathrm{CD}_{3} \mathrm{CN}\right)$ of $\mathbf{1} \cdot \mathrm{HPF}_{6}$ shows chemical shifts of the $\alpha$-and $\beta$-methyl groups at $\delta_{\mathrm{H}} 1.25$ and $\delta_{\mathrm{H}} 1.31$ ppm, respectively (Figure 4a). In comparison, the spectrum of the derived iminium ion $\mathbf{5}$ shows a remarkable reversal of the relative positions of the methyl groups, with the $\beta$-methyl group shifted upfield to $\delta_{\mathrm{H}} 0.82 \mathrm{ppm}$. This

(10) Burley, J. C.; Gilmour, R.; Prior, T. J.; Day, G. M. Acta Crystallogr. 2008, C64, o10. 


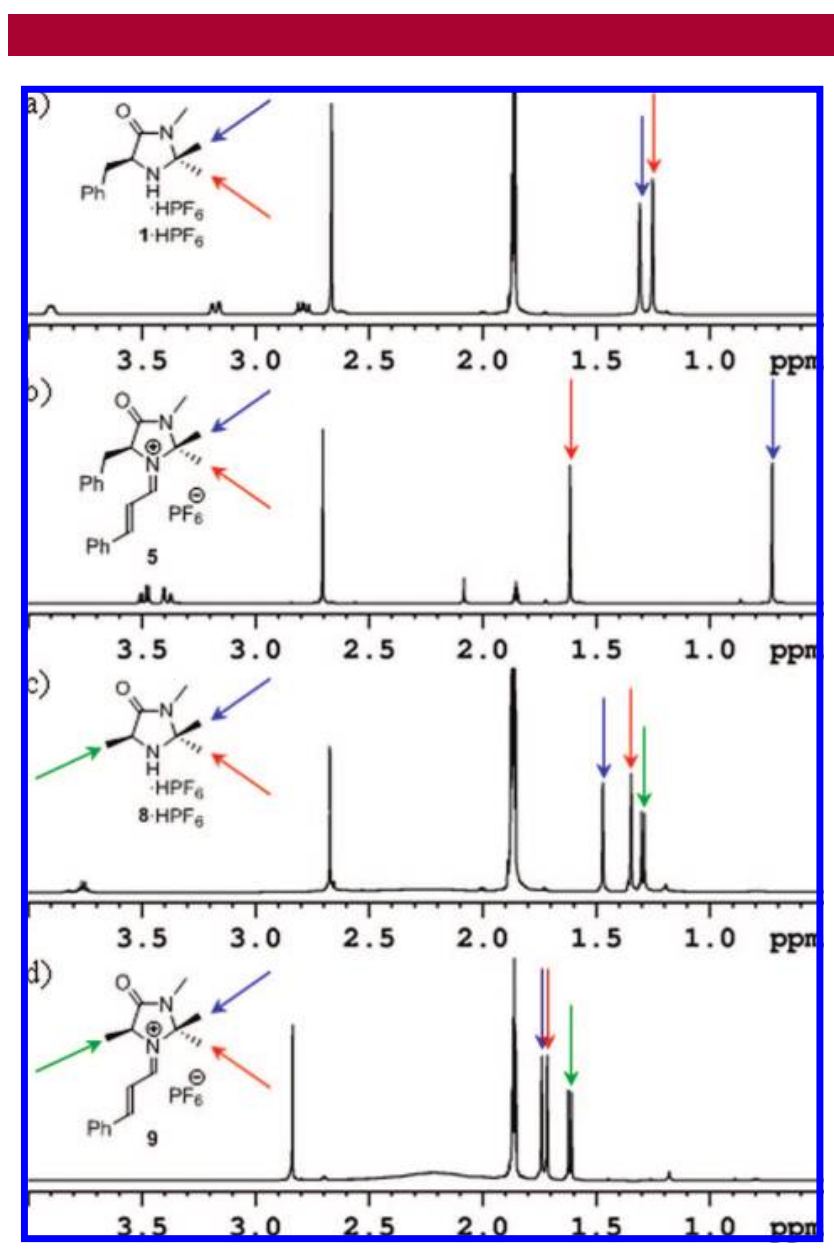

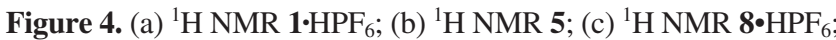
(d) ${ }^{1} \mathrm{H}$ NMR 9. All spectra obtained in $\mathrm{CD}_{3} \mathrm{CN}$.

represents a change in the relative chemical shifts of the methyl peaks $\left(\Delta \Delta \delta_{\mathrm{H}}\right)$ of $0.97 \mathrm{ppm}$ (Figure $\left.4 \mathrm{~b}\right)$. A similar effect is observed in the ${ }^{13} \mathrm{C}$ spectrum $\left(\Delta \Delta \delta_{\mathrm{C}}=4.62 \mathrm{ppm}\right)$. This effect is also observed with $\cdot \mathrm{HCl}$ salts in a variety of solvents (see Supporting Information), while Table 1 indi-

Table 1. Diels-Alder Cycloaddition between Cyclopentadiene and Cinnamaldehyde Catalysed by Imidazolidinone $\mathbf{1}^{a}$

\begin{tabular}{llccc}
\hline acid & solvent & endo/exo $^{b}$ & endo ee $^{c}$ & exo ee $^{c}$ \\
\hline $\mathrm{HCl}$ & $\mathrm{MeOH} / \mathrm{H}_{2} \mathrm{O}$ & $1: 1.3$ & 93 & 93 \\
$\mathrm{HPF}_{6}$ & $\mathrm{MeOH} / \mathrm{H}_{2} \mathrm{O}$ & $1: 1$ & 93 & 86 \\
$\mathrm{HPF}_{6}$ & $\mathrm{CH}_{3} \mathrm{CN} / \mathrm{H}_{2} \mathrm{O}$ & $1: 1.2$ & 93 & 89
\end{tabular}

${ }^{a}$ Reaction of cinnamaldehyde and cyclopentadiene in $\mathrm{MeOH} / \mathrm{H}_{2} \mathrm{O}(19$ : 1) or $\mathrm{CH}_{3} \mathrm{CN} / \mathrm{H}_{2} \mathrm{O}(19: 1), 1 \mathrm{M}, 25^{\circ} \mathrm{C}, 24 \mathrm{~h}, 20 \mathrm{~mol} \%$ cat. ${ }^{b}$ Ratio of endo/ exo determined by ${ }^{1} \mathrm{H}$ NMR. ${ }^{c}$ Determined by conversion to 2,4dinitrophenyl hydrazine derivative and examination by HPLC using chiracel OD-R. ${ }^{11}$

cates that use of $\mathbf{1} \cdot \mathrm{HPF}_{6}$ in acetonitrile does not significantly affect the stereochemical course of the reaction. We interpret this as evidence that one methyl group is shielded as a result of the proximity of the phenyl group and, hence, that the predominant solution conformation is similar to the X-ray structure. These NMR spectra are not consistent with conformation A.

Further evidence for the preferred conformation of the reactive iminium ion in solution came from preparation of the imidazolidinone $\mathbf{8}$ derived from alanine (see Supporting Information for full details). ${ }^{1} \mathrm{H}$ NMR spectra of $1 \cdot \mathrm{HPF}_{6}$ (Figure $4 \mathrm{a}$ ) and $\mathbf{8} \cdot \mathrm{HPF}_{6}$ (Figure $4 \mathrm{c}$ ) show similar chemical shifts for the methyl groups $\left(\delta_{\mathrm{H}} 1.25\right.$ and $\delta_{\mathrm{H}} 1.31 \mathrm{ppm}$ for $\mathbf{1} \cdot \mathrm{HPF}_{6}$ compared to $\delta_{\mathrm{H}} 1.35$ and $\delta_{\mathrm{H}} 1.47 \mathrm{ppm}$ for $\mathbf{8} \cdot \mathrm{HPF}_{6}$ ). However, formation of the corresponding iminium ion 9 by addition of cinnamaldehyde shows relatively little change in the positions of the methyl groups (Figure 4d), consistent with the absence of the shielding influence of an aromatic ring.

The effect of temperature on the ${ }^{1} \mathrm{H}$ NMR spectrum of iminium ion 5 is shown in Figure 5. This confirms that at lower temperatures the upfield shift of the $\beta$-methyl group is more pronounced $\left(\delta_{\mathrm{H}} @ 343.0 \mathrm{~K} 0.86 \mathrm{ppm} ; \delta_{\mathrm{H}} @ 242.8\right.$ $\mathrm{K} 0.56 \mathrm{ppm}$ ), consistent with our hypothesis that conformation $\mathbf{B}$ is thermodynamically preferred in solution. Additionally, increased temperature causes the chemical shift of $\mathrm{H}^{\mathrm{A}}$ of the iminium ion to decrease $\left(\delta_{\mathrm{H}} @ 343.0 \mathrm{~K} 7.11 \mathrm{ppm}\right.$; $\delta_{\mathrm{H}} @ 242.8 \mathrm{~K} 7.32 \mathrm{ppm}$ ), consistent with a larger proportion of molecules in solution adopting conformation $\mathbf{A}$ at higher temperatures.

Further confirmation comes from theoretical calculations (see Supporting Information for full data). In the gas phase, conformation $\mathbf{B}$ is approximately $5 \mathrm{~kJ} / \mathrm{mol}$ more stable than conformation $\mathbf{A}$, corresponding to approximately 9:1 ratio $\mathbf{A}: \mathbf{B}$ at room temperature. Unlike previous theoretical studies of this problem, ${ }^{8}$ the DF-SCS-LMP2/aug-cc-pVTZ method used here give a correct description of the weak interactions involved. ${ }^{12}$ A third conformation, with the benzyl arm located away from the imidazolidinone ring and the $\pi$-system, was also located, but was found to be more than $20 \mathrm{~kJ} / \mathrm{mol}$ higher in energy than the global minimum. Implicit solvation by $\mathrm{MeOH}$ or $\mathrm{MeCN}$ has only a minor effect on relative energies, changing the relative stability of conformations $\mathbf{A}$ and $\mathbf{B}$ by less than $2 \mathrm{~kJ} / \mathrm{mol}$ (see Supporting Information). NMR-GIAO calculations on the two low-energy conformations of $\mathbf{5}$ reproduce the features discussed above. Only conformation B shows significant difference in shielding between the $\alpha$ and $\beta$-methyl groups, with $\beta$-Me more shielded than $\alpha$-Me by $1.53 \mathrm{ppm}$. Conformation A has $\beta$-Me $0.14 \mathrm{ppm}$ less shielded than $\alpha$-Me. Quantitative comparison with experiment is complicated by solvent effects, but it is clear that the spectra shown in Figures 4 and 5 can only be explained by the predominance of conformation $\mathbf{B}$ in solution.

Location of the benzyl arm over the imidazolidinone ring, rather than the reactive $\pi$-system of the iminium ion, provides a rationale for the poor ee's observed when imidazolidinone $\mathbf{1}$ is used to catalyze conjugate addition reactions. ${ }^{13}$ For such

(11) Hall, A.; Harris, L. D.; Jones, C. L.; Tomkinson, N. C. O. Tetrahedron Lett. 2003, 44, 111.

(12) Hill, J. G.; Platts, J. A.; Werner, H.-J. Phvs. Chem. Chem. Phvs. 2006, 8,4072 .

(13) Austin, J. F.; MacMillan, D. W. C. J. Am. Chem. Soc. 2002, 124, 1172 . 


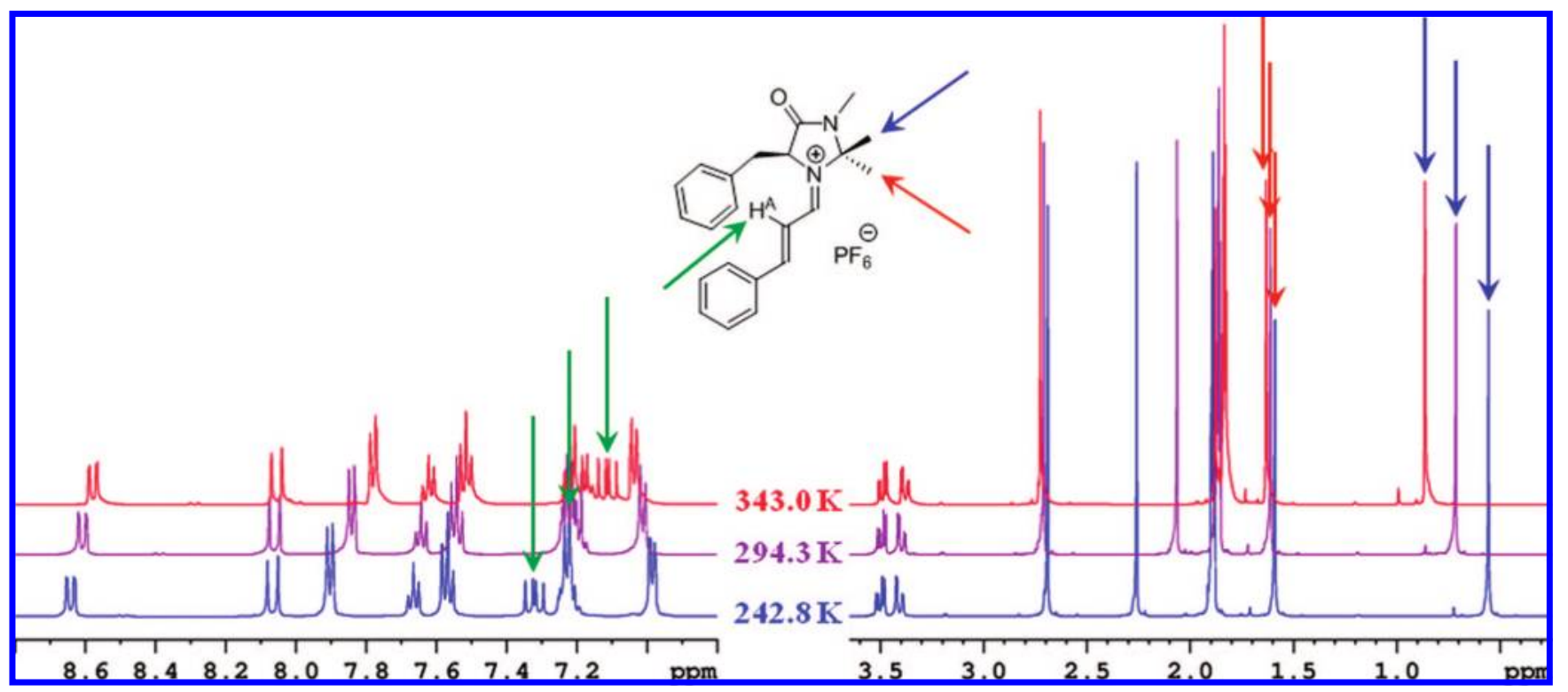

Figure 5. Variable temperature ${ }^{1} \mathrm{H}$ NMR data for iminium ion $\mathbf{5}$.

reactions, which have open transition states, the chiral space must be extended toward the reactive $\beta$-carbon of the iminium ion. This is achieved in catalyst $\mathbf{2}$ by the sterically demanding tert-butyl group which forces the benzyl arm over the reactive $\pi$-system. ${ }^{8 \mathrm{~b}}$ This highlights a critical design principle that must be adopted for imidazolidone based catalysts.

We have presented the first compelling experimental evidence showing that the preferred solution phase conformation of iminium ions derived from $\mathbf{1}$ has the benzyl arm located over the imidazolidinone ring and demonstrated the temperature dependence of these structures. Crucially, this is based on solution phase and solid state evidence, rather than solely from gas phase calculations, providing experimental verification of theoretical models. This link engenders confidence in computational results facilitating their integration into catalyst development and design. The insights gained, along with the methods identified for isolation and analysis of iminium ion intermediates can be applied to other catalysts to further verify working hypotheses and computational models and hence aid the rational design of new catalysts.

Acknowledgment. We thank the EPSRC for financial support under grant references GR/S69337/01 and EP/ E018718/1 and the Mass Spectrometry Service, Swansea for high-resolution spectra.

Supporting Information Available: Analytical data, experimental procedures, NMR spectra, and X-ray data. This material is available free of charge via the Internet at http://pubs.acs.org.

OL802512Y 